\title{
Identification and Management of Cobalt Toxicity: A Case Report of Rapidly Progressing Toxicity after Hip Arthroplasty Revision
}

\author{
Neena Mohan, MD \\ Thomas Jefferson University Hospital, neena.mohan@jefferson.edu \\ Eric Kasprowicz, MD \\ Thomas Jefferson University, eric.kasprowicz@jefferson.edu
}

Follow this and additional works at: https://jdc.jefferson.edu/tmf

Part of the Internal Medicine Commons

Let us know how access to this document benefits you

\section{Recommended Citation}

Mohan, MD, Neena and Kasprowicz, MD, Eric (2016) "Identification and Management of Cobalt Toxicity: A Case Report of Rapidly Progressing Toxicity after Hip Arthroplasty Revision," The Medicine Forum: Vol. 17 , Article 18.

DOI: https://doi.org/10.29046/TMF.017.1.019

Available at: https://jdc.jefferson.edu/tmf/vol17/iss1/18

This Article is brought to you for free and open access by the Jefferson Digital Commons. The Jefferson Digital Commons is a service of Thomas Jefferson University's Center for Teaching and Learning (CTL). The Commons is a showcase for Jefferson books and journals, peer-reviewed scholarly publications, unique historical collections from the University archives, and teaching tools. The Jefferson Digital Commons allows researchers and interested readers anywhere in the world to learn about and keep up to date with Jefferson scholarship. This article has been accepted for inclusion in The Medicine Forum by an authorized administrator of the Jefferson Digital Commons. For more information, please contact: JeffersonDigitalCommons@jefferson.edu. 


\section{Identification and Management of Cobalt Toxicity: A Case Report of Rapidly Progressing Toxicity after Hip Arthroplasty Revision}

Neena Mohan, MD and Eric Kasprowicz, MD

\section{INTRODUCTION}

Patients undergoing total hip arthroplasty represent a growing portion of the population. More than 330,000 hip replacements are performed annually', and more than 2.5 million Americans are living with a hip prosthesis ${ }^{2}$ Many hardware configurations utilize metal alloys for the femoral head and/or acetabulum. Although their use is decreasing due to safety concerns, cobalt-chromium femoral heads were still used in 51\% of total hip arthroplasties in 2014 ${ }^{3}$. There is rising concern about the adverse effects of metal ions released from these joint replacements. However, little published evidence is available supporting specific interventions for the management of cobalt toxicity

Given the increasing incidence and prevalence of total hip arthroplasty in the United States, patients with total hip replacements will become more commonplace in the internist's practice. With the risk of adverse effects related to these prostheses, it is important to be familiar with the presentation of cobalt toxicity in order to spare patients from excessive or irreversible damage.

\section{CASE PRESENTATION}

The patient is a 61 year-old female with a past medical history of total hip arthroplasty in 2004 with a ceramic prosthesis who had a cobalt-chromium prosthetic revision in May 2015. The old prosthesis was found to be shattered during the second operation, and although attempts were made to extract all the fragments, it was noted that the surgeons were unable to remove all of the particulate ceramic debris. Two months later, the patient began noticing bilateral hearing loss and blurry vision that progressively worsened, as well as peripheral neuropathy in her hands and feet. She also developed hypothyroidism and was started on levothyroxine. Due to persistent abdominal pain, decreased appetite and weight loss, the patient had an endoscopy which revealed severe gastritis. At an outpatient neurology evaluation, the patient's whole blood cobalt level was found to be 2,128 $\mathrm{mcg} / \mathrm{L}$ (reference $<3 \mathrm{mcg} / \mathrm{L}$ ). She was admitted to Thomas Jefferson University Hospital for management of progressively worsening symptoms and for hip arthroplasty revision evaluation.

The patient's initial serum cobalt level during hospitalization was $1254 \mathrm{mcg} / \mathrm{L}$ (reference 0.1-0.4 mcg/L) and the whole blood cobalt level was 1997.0 mcg/L (reference

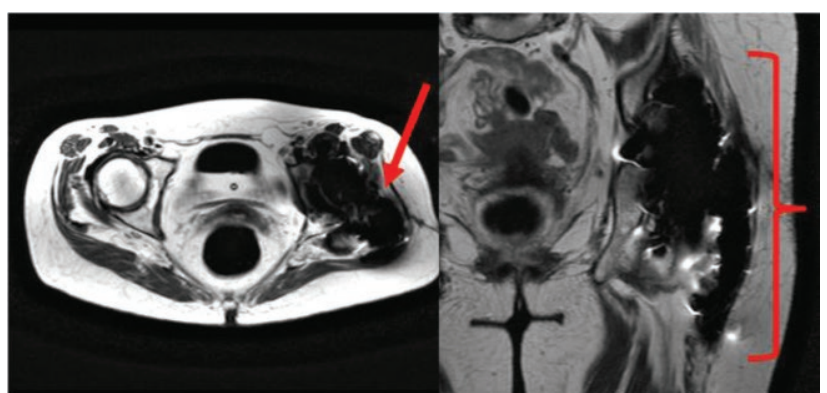

Figure 1. Cross-sectional MRI imaging with Metal Artifact Reduction Sequence (MARS) Protocol to diminish the signal intensity from metallic objects demonstrates local invasion of metallic content into tissue surrounding the joint

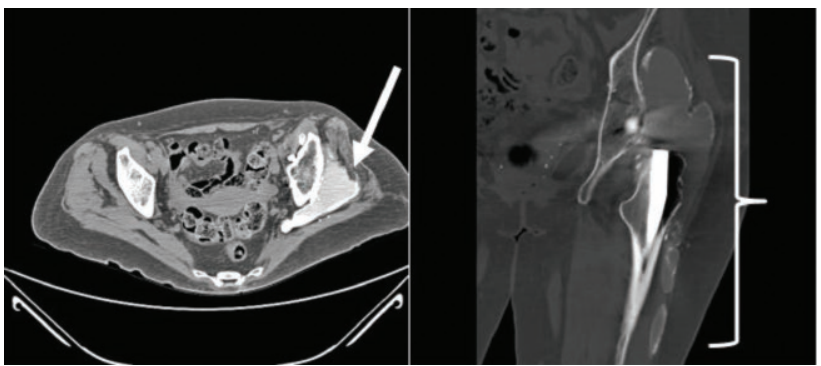

Figure 2. Cross-sectional CT imaging of the patient's affected hip, demonstrating extensive local tissue inflammation extending along the affected joint.

$<1.8 \mathrm{mcg} / \mathrm{L})$. Physical examination revealed decreased visual acuity and decreased hearing bilaterally. She had decreased reflexes in the lower extremities bilaterally and intact sensation. Lower extremity strength bilaterally was limited by pain

\section{DIFFERENTIAL DIAGNOSIS}

Given the patient's constellation of symptoms and lack of other significant past medical history, the differential in this case was relatively limited. The important lesson from this case is the need to identify symptoms of cobalt toxicity early in patients with prior hip arthroplasty. Clinically significant effects of cobalt poisoning rarely appear below a whole blood level of $300 \mathrm{mcg} / \mathrm{L}^{4}$. Above this level, patients may begin to develop many of the same symptoms displayed here: neurotoxicity including optic nerve damage, thyroid toxicity, and fatigue and weakness 5 . Cases of severe cobalt toxicity have even led to mortality from worsening dilated cardiomyopathy 


\section{The Medicine Forum, Vol. 17 [2016], Art. 18}

\section{OUTCOME AND FOLLOW-UP}

Early in the admission, CT and MRI of the hip demonstrated a large area of metallic infiltration (Figure 1) and inflammation (Figure 2) in the surrounding tissues. Nephrology recommended plasmapheresis to attempt to reduce the cobalt burden. On the initial day of plasmapheresis, the patient's whole blood cobalt level was 1891 $\mathrm{mcg} / \mathrm{L}$. The next day, the whole blood cobalt level had fallen to $1509 \mathrm{mcg} / \mathrm{L}$. Orthopedic surgery performed a left hip arthroplasty revision, during which time a significant amount of cobalt was found and removed from the joint. After the operation, the whole blood cobalt level had decreased to $447 \mathrm{mcg} / \mathrm{L}$.

During the hospitalization, plasmapheresis was eventually discontinued, as there was little literature to support its use in cobalt toxicity and it did not significantly reduce cobalt levels. Chelation was recommended, and patient received one day of treatment with $\mathrm{N}$-acetylcysteine (NAC) after her operation.

Other complications which arose during the hospitalization included lactic acidosis and diabetes insipidus, thought to be secondary to cobalt toxicity. These complications, along with the patient's severe gastritis, have not previously been attributed to cobalt toxicity in the literature. However, given the patients few medical comorbities and onset corresponding with the elevation in cobalt levels, it is likely that they may represent previously undescribed complications of cobalt toxicity. The patient's vision loss was attributed by ophthalmology to optic neuropathy and possible retinal toxicity from cobalt. After 20 days of hospitalization, the patient's decreased visual acuity and hearing were only mildly improved, her peripheral neuropathy persisted, and her thyroid stimulating hormone level was $29.47 \mathrm{ulU} / \mathrm{mL}$ (nl 0.3-5.0 ulU/mL). The whole blood cobalt level after a second left hip irrigation prior to discharge was $247 \mathrm{mcg} / \mathrm{L}$.

\section{DISCUSSION AND MANAGEMENT}

A notable element of this case is the accelerated development of toxicity after recent revision. This has been found most commonly after shattering of a ceramic joint $(5,6)$. Revisions are complicated by an inability to completely remove all the shattered ceramic components, and it is believed that retained particles create shearing in the newly placed joint that accelerates the release of metal ions.

There is no consensus regarding management of patients with systemic symptoms of cobalt toxicity. Clinical response to different treatments is not consistently documented in current literature. The main objective is to eliminate exposure to cobalt and treat systemic symptoms supportively, such as with thyroid hormone replacement therapy for hypothyroidism, and beta blockers and diuretics for cardiomyopathy?

In a study evaluating the effects of administration of glutathione, NAC, 2,3-dimercaptosuccinic acid (DMSA), ethylendiamine-tetraacetic acid (EDTA), and diethylentriamepentaacetic acid (DTPA) for five days in rats, the urinary excretion of cobalt was significantly increased by glutathione, NAC and DTPA. However, the concentration of cobalt in the various tissues of the body was only decreased by NAC (liver and spleen) and glutathione (spleen) ${ }^{8}$. EDTA has been the predominant chelator administered to humans. In a 2011 study, it provided short-term lowering of blood cobalt measurements; however, cobalt concentrations rebounded within days. This trend occurs because while EDTA binds and removes part of the soluble ions present in plasma, there continues to be further release of ions from the active surface?

There is little human evidence available to support recommendations for cobalt chelation. The National Council on Radiation Protection and Measurements and the Radiation Emergency Assistance Center/Training Site recommend DTPA for cobalt radionuclide chelation, while also stating that DMSA, EDTA, and NAC can be considered. For non-radiologic exposure, other sources suggest that both NAC and EDTA can be considered, without a definitive recommendation ${ }^{10}$.

There is no conclusive evidence regarding the utility of plasmapheresis in cobalt toxicity. In one case of a 22 year old male with oral dichromate intoxication, five treatment sessions of plasmapheresis significantly lowered his serum and urinary chromium concentrations ${ }^{11}$. This case report contributed to the consideration of plasmapheresis as part of the management plan in our patient.

Revision surgery appears to be effective in removal of the systemic cobalt burden. A 2015 study evaluated blood metal ion levels in patients who underwent revision surgery for adverse effects due to cobalt and chromium debris. There was a decrease in blood cobalt in all patients who had unilateral surgery at one year of follow up. In some patients with bilateral metal-on-metal hip prostheses, cobalt levels remained elevated, but this could be attributed to the confounding effect of the contralateral metal-on-metal implant ${ }^{12}$.

\section{KEY POINTS}

- Patients with elevated cobalt blood levels after metalcontaining total hip arthroplasties are at risk for significant clinical sequelae, including vision and hearing loss, peripheral neuropathy, hypothyroidism, and cardiomyopathy.

- Severe gastritis, lactic acidosis and diabetes insipidus may also be seen in cobalt toxicity.

- There is currently no consensus regarding the appropriate management of cobalt toxicity. These patients should be considered for prosthetic revision to attempt to decrease cobalt systemic burden. Chelation with NAC and EDTA may be used as adjunctive therapy. Additional research is warranted to evaluate the optimal timing of revision surgeries and chelation therapy. 


\section{REFERENCES}

1. Centers for Disease Control - National Center for Health Statistics. Inpatient Surgery. CDC FastStats. 2014. Retrieved from the web at: http://www.cdc.gov/ nchs/fastats/inpatient-surgery.htm

2. Kremers H, Larson D, Crowson C, Kremers W, Washington R, Steiner C, Jiranek W, Berry D. Prevalence of Total Hip and Knee Replacement in the United States. The Journal of Bone \& Joint Surgery. 2015; 97(17): 1386-1397

3. American Joint Replacement Registry. Hip Arthroplasty. The Annual Report 2014 2014. Retrieved from the web at: http://www.ajrr.net/publications-data

4. Paustenbach DJ, Galbraith DA, Finley BL. Interpreting cobalt blood concentrations in hip implant patients. Clinical Toxicology. 2014;52(2):98-112

5. Bradberry SM, Wilkinson JM, Ferner RE. Systemic toxicity related to metal hip prostheses. Clinical Toxicology. 2014; 52(8):837-47

6. Zywiel MG, Brandt JM, Overgaard CB, Cheung AC, Turgeon TR, Syed KA. Fatal cardiomyopathy after revision total hip replacement for fracture of a ceramic liner. The Bone \& Joint Journal. 2013; 95-B(1):31-7
7. Devlin JJ, Pomerleau AC, Brent J, Morgan BW, et al. Clinical Features, Testing, and Management of Patients with Suspected Prosthetic Hip-Associated Cobalt Toxicity: a Systemic Review of Cases. Journal of Medical Toxicology. 2013; 9(4):405-15

8. Llobet JM, Domingo JL, Corbella J, et al. Comparative effects of repeated parenteral administration of several chelators on the distribution and excretion of cobalt. Research Communications in Chemical Pathology $\&$ Pharmacology. 1988 May; 60(2):225-33

9. lacobellis C, Berizzi A, Pozzuoli A, et al. Normalization of chromium and cobalt values after femoral head replacement. Int J Surg Care Rep. 2015; 10: 146-150.

10. Smith SW. The Role of Chelation in the Treatment of Other Metal Poisonings Journal of Medical Toxicology. 2013; 9:355-369.

11. Illner N, Gerth J, Pfeiffer R, et al. "Nearly a stairway to heaven"-severe dichromate intoxication in a young man. Clinical Nephrology. 2009; (3): 338-41.

12. Lainiala O, Reito A, Elo P, Pajamaki J, Puolakka T, Eskelinen A. Revision of Metal-on-metal Hip Prostheses Results in Marked Reduction of Blood Cobalt and Chromium lon Concentrations. Clinical Orthopaedics and Related Research. 2015; 473(7):2305-13

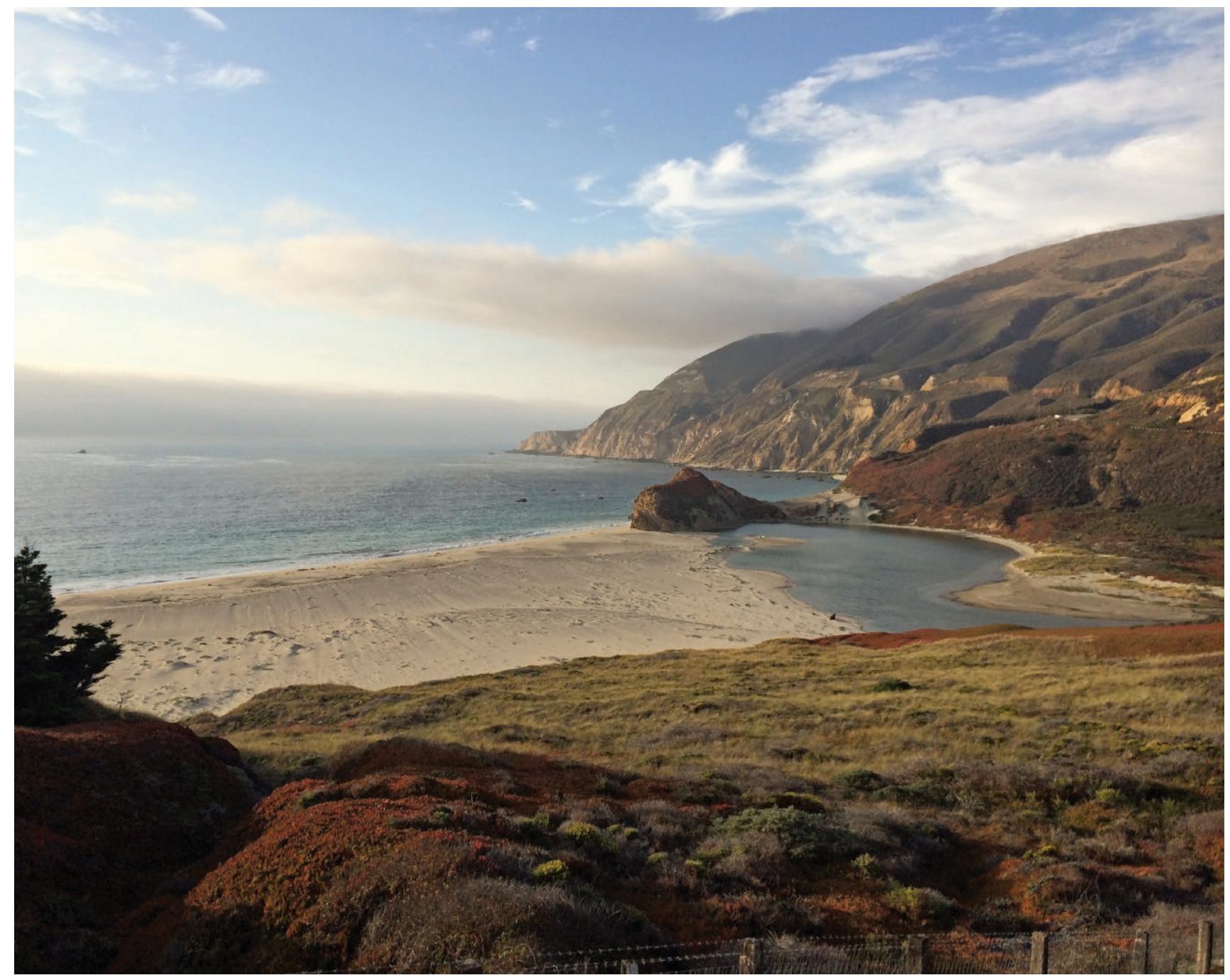

